\title{
ANALISIS RENTABILITAS USAHA TERNAK ITIK PETELUR DI DESA WOLAANG KECAMATAN LANGOWAN TIMUR KABUPATEN MINAHASA
}

\author{
Bella Gladys Endoh*, A. Makalew, M. A. V Manese, T. F. D Lumy \\ Fakultas Peternakan Universitas Sam Ratulangi Manado 95115
}

\begin{abstract}
ABSTRAK
Penelitian ini dilakukan di Desa Wolaang Kecamatan Langowan Timur Kabupaten Minahasa pada tanggal 8 Agustus sampai dengan 5 September 2015. Penelitian ini bertujuan untuk mengetahui tingkat rentabilitas usaha ternak itik petelur di Desa Wolaang. Metode penelitian yang digunakan adalah metode survei. Desa Wolaang ditetapkan sebagai lokasi penelitian secara purposive sampling dengan pertimbangan bahwa : Desa yang memiliki populasi ternak itik petelur terbanyak ( 5924 ekor), areal sawa terluas $(161,35 \mathrm{Ha})$, dan jumlah peternak itik petelur terbanyak (20 Peternak). Data yang diambil meliputi data primer dan data sekunder. Model analisis yang digunakan adalah analisis rentabilitas dengan formulasi : $\mathrm{R}=\mathrm{L} / \mathrm{M} \times 100 \%$. Hasil penelitian diperoleh bahwa tingkat pendidikan responden $60 \%$ SD, $25 \%$ SMP, dan 15\% SMA. Lama berusaha 110 tahun 25\%, 11-20 tahun 20\%, 21-30 tahun $25 \%, 31-40$ tahun $15 \%, 41-50$ tahun $10 \%$ dan diatas 51 tahun 5\%. Hasil analisis rentabilitas diperoleh nilai $\mathrm{R}=69 \%$ artinya dengan penggunaan modal
\end{abstract}

*Korespondensi (corresponding Author)

Email: endohgladys@yahoo.com investasi Rp.100.000,- mampu menghasilkan laba sebesar Rp 69.000,-. Capaian nilai R melebihi suku bunga deposito bank BRI $(6,50 \%)$. Berdasarkan hasil dan pembahasan dapat disimpulkan bahwa untuk Rentabilitas usaha ternak itik petelur sebesar $\mathrm{R}=69 \%$ dan rentabilitas usaha ternak itik petelur lebih besar dari tingkat suku bunga deposito Bank BRI yang berlaku.

Kata Kunci : Itik Petelur, Modal, Rentabilitas

ABSTRACT

\section{RENTABILITY ANALYSIS OF}

LAYING DUCK FARM AT THE WOLAANG VILLAGE LANGOWAN TIMUR DISTRICT OF MINAHASA REGENCY. Study was conducted at Wolaang village, East Lagowan district of Minahasa regency on August 8 to September 5, 2015. The objective of this study was to evaluate the rentability laying duck farm at the Wolaang village. Survey method was applied in this study. Wolaang village was defined as study location and chosen the purposive sampling based on consideration of the highest duck population (5924 heads), widest wet rise areas of 161.35 ha, and more than 20 animal farmers. Data of primary and secondary bases were used in this study. Rentability analysis model 
was applied using formula, $\mathrm{R}=\mathrm{L} / \mathrm{M} \times 100 \%$. Results showed that animal farmer education was 60 percents passed the elementary school, 25 percents passed junior high school and 15 percents passed senior high school. The period of raising animals of the 1- to 10-year experience was 25 percents, the period of the 11- to 20 year experience was 20 percents, that of the 21- to 30 year experience was 25 percents, that of the 31- to 40-year experience was 15 percents, that of the 41 - to 50-year experience was 10 percents, and that of more than 50-year experience was 5 percents. The rentability analysis found the value of 69 percents indicating that the use of infestation financial capital of IDR 100,000.- was able to gain the benefit of the IDR 60,000.-. The reach of the values of $\mathrm{R}$ was more than the deposit rent of the BRI bank of 6.5 percents. Therefore, it can be concluded that farm rentability of laying duck was more than the BRI bank deposit rent.

Key word: Laying duck, rentability.

\section{PENDAHULUAN}

Tujuan pembangunan nasional intinya menciptakan masyarakat yang adil dan makmur. Dalam pencapaian tujuan pembangunan ini, pemerintah mengeluarkan kebijakan pembangunan di sektor pertanian yang hakekatnya bertujuan untuk meningkatkan kesejahteraan atau taraf hidup petani (Prayitno, 1987).

Usaha peternakan unggas di Indonesia saat ini mengalami perkembangan yang relatif lebih maju dibandingkan usaha ternak yang lain, Hal tersebut dapat dilihat dari kontribusinya yang cukup besar dalam memperluas lapangan kerja, peningkatan pendapatan masyarakat dan yang utama adalah pemenuhan kebutuhan makanan bernilai gizi tinggi. Salah satu ternak unggas yang mulai berkembang, dimasyarakat adalah ternak itik, meskipun tidak sepopuler ternak ayam. Itik mulai disukai masyarakat untuk diusahakan sehingga usaha ternak itik semakin berkembang (Lembong 2015). Itik memiliki kelebihan yaitu memiliki daya tahan terhadap penyakit yang lebih baik dibandingkan unggas lainnya, oleh karena itu ternak itik memiliki resiko kegagalan akibat penyakit yang relatif lebih kecil (Raharjo, 2009).

Populasi itik di Kabupaten Minahasa pada tahun 2013 berjumlah 60.711 ekor dan pada tahun 2014 mencapai 63.813 ekor. Data tersebut menunjukan bahwa populasi ternak itik mengalami peningkatan. Ternak Itik telah menjadi salah satu pilihan usaha sebagai penyedia telur dan daging sehingga dapat dijadikan ternak andalan. (Sipora., 2009 dan Kateran 2002).

Usaha peternakan itik memiliki prospek usaha yang cukup potensial untuk dikembangkan maupun untuk dipasarkan baik usaha pokok maupun sebagai usaha sampingan serta membantu dalam meningkatkan 
pendapatan dan taraf hidup masyarakat. Berdasarkan hasil penelitian, Kecamatan Langowan Timur merupakan salah satu Kecamatan penghasil telur itik di Kabupaten Minahasa. Keadaan Peternak itik dapat dilihat pada Tabel 1. Hasil penelitian pada tanggal 8 Agustus sampai dengan 5 September 2015 menunjukan bahwa dari 8 Desa yang ada di Kecamatan Langowan Timur yang paling besar populasi ternak itik berada di Desa Wolaang dengan jumlah 5.924 ekor dengan luas sawah sebesar 161,35 Ha.

Hal ini dimungkinkan karena ditunjang tersedianya areal persawahan dan memiliki sarana air yang cukup juga iklim yang menunjang untuk usaha ternak itik petelur. Usaha ternak itik di desa Wolaang sudah berlangsung secara turun temurun, namun belum diteliti apakah usaha ini mempunyai laba yang lebih besar dari suku bunga deposito bank atau tidak, sehingga saya ingin melakukan penelitian untukmenganalisis tingkat rentabilitas dari usaha ternak itik petelur tersebut. Permas alahannya, Apakah usaha ternak itik di desa Wolaang memiliki nilai Rentabilitas yang lebih besar dari suku bunga deposito bank atau tidak, belum diketahui. Berdasarkan latar belakang dan permasalahan maka penelitian ini bertujuan untuk menganalisis rentabilitas usaha peternakan itik petelur di Desa Wolaang Kecamatan Langowan Timur. Hasil penelitian $\begin{array}{llll}\text { pada } & \text { tanggal } & 8 & \text { Agustus }\end{array}$

Tabel 1. Jumlah Desa, Jumlah Peternak, Luas Sawah dan Jumlah Ternak Itik.

\begin{tabular}{llccc}
\hline No & \multicolumn{1}{c}{ Desa } & $\begin{array}{c}\text { Jumlah } \\
\text { Peternak }\end{array}$ & $\begin{array}{c}\text { Luas Sawah } \\
(\mathrm{Ha})\end{array}$ & $\begin{array}{c}\text { Jumlah Ternak Itik } \\
(\text { Ekor })\end{array}$ \\
\hline 1 & Teep & 4 & 67 & 576 \\
2 & Karondoran & 5 & 57 & 576 \\
3 & Waleure & 2 & 16 & 262 \\
4 & Sumarayar & 3 & 30 & 418 \\
5 & Wolaang & 20 & 161,35 & 5,924 \\
6 & Amongena Satu & 10 & 110 & 1.400 \\
7 & Amongena Dua & 14 & 142 & 1.556 \\
8 & Amongena Tiga & 12 & 88 & 1.115 \\
\hline & & & 671,35 & 11,578 \\
\hline
\end{tabular}

Sumber : Kantor Kecamatan Langowan Timur, tahun 2015 
sampai dengan 5 September 2015 menunjukan bahwa dari 8 Desa yang ada di Kecamatan Langowan Timur yang paling besar populasi ternak itik berada di Desa Wolaang dengan jumlah 5.924 ekor dengan luas sawah sebesar 161,35 Ha.

\section{METODE PENELITIAN}

Penelitian ini dilaksanakan di Desa Wolaang Kecamatan Langowan Timur Kabupaten Minahasa. Waktu penelitian dilaksanakan pada tanggal 8 Agustus sampai 5 September 2015. Metode penelitian yang digunakan adalah metode survei. Desa Wolaang ditetapkan sebagai lokasi penelitian secara purposive sampling dengan pertimbangan bahwa : Desa yang memiliki populasi ternak itik petelur terbanyak ( 5924 ekor), areal sawa terluas (161,35 Ha), dan jumlah peternak itik petelur terbanyak (20 peternak). Penentuan sampel sebagai responden dilakukan secara total sampling terhadap peternak itik petelur dengan jumlah responden sebanyak 20 orang. Data yang diambil yaitu data primer dan sekunder. Data primer diperoleh dari wawancara langsung dengan responden atau peternak dengan menggunakan daftar pertanyaan (kuesioner) yang sudah dibuat, sedangkan
Data sekunder diperoleh dari instansiinstansi pemerintah yang terkait yakni Dinas Pertanian Dan Peternakan Kabupaten Minahasa dan Kantor Kecamatan Langowan Timur.

Metode analisis data yang digunakan adalah analisis Rentabilitas dengan formulasi seperti pada persamaan (1) menurut Riyanto (1999) sebagai berikut :

$$
\mathrm{R}=\frac{\mathrm{L}}{\mathrm{M}} \mathrm{X} 100 \%
$$

Keterangan :

$\mathrm{R}$ : Rentabilitas

L :Jumlah laba yang diperoleh selama periode tertentu

M : Modal atau Aktiva yang

dikeluarkan untuk menghasilkan laba tersebut.

\section{HASIL DAN PEMBAHASAN}

Kecamatan Langowan Timur terletak pada wilayah Kabupaten Dati II Minahasa, Propinsi Sulawesi Utara, Kecamatan langowan Timur memiliki 8 Desa yaitu : Teep, Karondoran, Waleure, Sumarayar, Wolaang, 
Amongena I, Amongena II, Amongena

III, dengan batas-batas Wilayah:

- Sebelah utara berbatasan dengan Kecamatan Tompaso

- Sebelah timur berbatasan dengan kecamatan Kakas

- Sebelah selatan berbatasan dengan Laut Maluku

- Sebelah barat berbatasan dengan Kecamatan Langowan Barat.

Luas Kecamatan Langowan Timur $68 \mathrm{Km}^{2}$ dengan ketinggian 600-700 meter dari permukaan laut. Pusat kota Kecamatan Langowan Timur terletak $30 \mathrm{Km}$ dari Manado ibukota propinsi Sulawesi Utara. Sarana perhubungan dari Tondano dan Manado ke wilayah Kecamatan Langowan Timur baik, dengan kondisi jalan yang beraspal.

Kondisi kandang tidak harus dari bahan yang mahal tetapi cukup sederhana asal tahan lama (kuat). Kandang merupakan hal yang sangat penting dalam menunjang keberhasilan usaha, karena kandang berfungsi untuk melindungi ternak dari hujan dan panas sinar matahari, pencuri dan untuk memudahkan tatalaksana seperti pemberian pakan dan pada saat mengambil hasil dari usaha ternak itik yaitu telur itik.
Berdasarkan hasil pengamatan dilokasi penelitian, untuk kandang itik terletak di pinggiran sawah. Kandang itik terbuat dari jaring atau biasa disebut Net, Terpal untuk melindungi dari hujan, dan lantai kandang dialasi jerami-jerami, untuk ukuran kandang berbeda-beda sesuai dengan jumlah ternak itik yang dipelihara, dan pada saat itik akan dipindahkan ke tempat lain maka kandang tersebut dapat digulung kembali dan dapat digunakan di tempat yang baru.

Pakan merupakan faktor yang sangat menentukan dalam usaha peternakan itik, karena $60-70 \%$ biaya produksi adalah biaya paka. Dari hasil penelitian, Pemberian pakan pada ternak itik di desa Wolaang dilakukan 3 kali sehari yaitu pada pukul 08:00, 12:00, dan Pukul 05:00. Pakan yang diberikan selain ceceran-ceceran padi peternak memberikan jagung dan keong atau sering disebut biak. Untuk pakan jenis keong/biak biasanya dalam sebulan ada sekitar 8 kali (1 minggu 2 kali) dimana pakan tersebut tidak masuk ke peternak dan sebagai gantinya ternak itik harus digembalakan untuk mencari ceceranceceran padi dan harus diawasi oleh peternak agar tidak masuk kelahan sawah yang memakai racun, obat, 
pestisida dan sebagainya yang dapat membahayakan kesehatan ternak itik. Berdasarkan hasil penelitian jenis itik yang dipelihara adalah itik Lokal. Ternak itik petelur di desa Wolaang pada umumnya di pelihara secara sistim boro diterapkan pada itik umur diatas 1 bulan sampai dengan itik dewasa atau pada fase layer. Pada pemeliharaan sistim boro atau gembala, tempat pemeliharaan itik berpindah-pindah untuk mencari tempat penggembalaan yang banyak tersedia pakan, misalnya sawah yang baru dipanen. Pemeliharaan sistim boro ini untuk menekan tingginya biaya pakan terutama pada fase bertelur. Sistim ini banyak diusahakan secara turun temurun oleh peternak yang ada di desa Wolaang. Mereka memanfaatkan jeda waktu antara musim panen dengan musim tanam padi untuk memelihara itik muda-dewasa itu di sawah. Pada kondisi tersebut terdapat ceceran padi sebagai sumber pakan ternak itik yang digembalakan, selain pakan alami berupa cacing, katak, keong, serangga air, belalang dan sebagainya (Yuwono 2012). Biaya produksi digolongkan menjadi biaya tetap dan biaya tidak tetap (Taufik, 2013 dan Supriyadi 2011). perubahan aktivitas produksinya dan biaya tidak tetap ialah biaya yang jumlahnya berubah-ubah sesuai dengan besarnya produksi. Penggunaan biaya dalam hal ini meliputi biaya tetap dan biaya tidak tetap. Biaya tetap meliputi biaya pembuatan kandang (jaring dan tali) $0,6 \%$, dan ternak itik 21,6\%, sedangkan biaya tidak tetap meliputi : biaya pakan 55,4\%, upah tenaga kerja $20,6 \%$ dan biaya transportasi $1,8 \%$. Berdasarkan hasil penelitian untuk biaya ternak itik hanya berlaku dalam 1periode yaitu antara 1-3 tahun produksi,rata-rata biaya tetap dan biaya tidak tetap per responden berjumlah Rp. 61.221.625/tahun.

Keuntungan usaha khususnya usaha peternakan merupakan bagian yang sangat diperhitungkan karena dari banyaknya keuntungan inilah seorang pengusaha termotivasi untuk lebih mengembangkan usaha peternakannya. Harga jual telur itik kepada para pedagang maupun kepada konsumen akhir dihitung berdasarkan harga per butir telur Rp. 1.500,-, dan untuk itik afkir dijual dengan harga 55,000 per ekor. Hasil penelitian menunjukan bahwa, telur yang dihasilkan oleh peternak itik petelur dalam 1 hari untuk 5924 ternak itik mampu menghasilkan 
telur itik sebanyak 3720 butir/hari. Sitem pemasaran yang sudah terbentuk di desa Wolaang ialah para pedagang pengencer, pedagang pengumpul, dan konsumen akhir langsung mendatangi rumah peternak. Sistem pembayaran yang berlaku yaitu sistem cash dan sistem kredit (diberlakukan khusus pedagang yang sudah menjadi pelanggan tetap). Hal ini tercipta karena antara peternak dan pedagang sudah saling percaya dan para pedagang hanya berdomisili di Kecamatan Langowan.

Tabel 2. Rata-rata Biaya Tetap dan Biaya Tidak Tetap Pada Usaha Ternak Itik Petelur

\begin{tabular}{|c|c|c|c|}
\hline Uraian Biaya & Jumlah & $\begin{array}{l}\text { Rata-rata } \\
\text { (Rp/responden) }\end{array}$ & $\begin{array}{l}\text { Persentasi } \\
(\%)\end{array}$ \\
\hline \multicolumn{4}{|l|}{ 1. Biaya Tetap } \\
\hline Biaya pembuatan kandang & 7.530 .000 & 376.500 & 0,6 \\
\hline Itik & 266.580 .000 & 13.329 .000 & 21,6 \\
\hline \multirow{2}{*}{\multicolumn{4}{|c|}{$\begin{array}{l}\text { 2. Biaya Tidak Tetap } \\
\text { a. Biaya Pakan }\end{array}$}} \\
\hline & & & \\
\hline -Biak & 376.600 .000 & 18.830 .000 & 31 \\
\hline -Jagung & 298.935 .000 & 14.946 .750 & 24,4 \\
\hline b. Tenaga Kerja & 253.087 .500 & 12.654 .375 & 20,6 \\
\hline c. Transportasi & 21.700 .000 & 1.085 .000 & 1,8 \\
\hline Total & 1.224 .432 .500 & 61.221 .625 & 100 \\
\hline
\end{tabular}

Tabel 3. Rata-rata Penerimaan Usaha Ternak Itik Petelur (Rp/tahun).

\begin{tabular}{llrlr}
\hline No & Penerimaan & Jumlah & \multicolumn{1}{l}{$\begin{array}{l}\text { Total Penerimaan } \\
\text { Rp/tahun }\end{array}$} & $\begin{array}{l}\text { Rata-rata } \\
\text { (Rp/responden) }\end{array}$ \\
\hline 1 & $\begin{array}{l}\text { Telur itik } \\
(1.500 / \text { Butir) }\end{array}$ & 1.370 .940 & 2.036 .700 .000 & 101.835 .000 \\
2 & $\begin{array}{l}\text { Itik afkir } \\
\text { (55.000/Ekor) }\end{array}$ & 660 & 36.300 .000 & 1.815 .000 \\
\hline & Jumlah & & 2.073 .000 .000 & 103.650 .000 \\
\hline
\end{tabular}




$$
\text { Rata-rata harga tersebut }
$$
merupakan harga yang diberlakukan oleh peternak dan disesuaikan dengan harga pasar. Total Keuntungan usaha ternak itik petelur dapat dilihat pada perhitungan sesuai persamaan (2).

$$
\begin{gathered}
\Pi=\mathrm{TR}-\mathrm{TC} \\
\Pi=103.650 .000-61.221 .625 \\
\mathrm{Rp}=42.428 .375 / \text { tahun/responden. }
\end{gathered}
$$

Berdasarkan hasil persamaan (2) maka keuntungan usaha ternak itik petelur di desaWolaang sebesar Rp. 42.428.375/tah un/responden.

Berdasarkan sisi finansial, kemampuan perusahaan menghasilkan laba selama periode tertentu disebut rentabilitas (Riyanto, 1999; Waston \& Capeland, 1995, Nitisemito, 1978 dan Riadi, 2006).

Nilai rentabilitas yang diterima oleh peternak itik petelur di desa Wolaang bervariasi mulai

dari 0.26 sampai dengan 0,95 . Dengan nilai rata-rata $\mathrm{R}=69 \%$. Berdasarkan hasil analisis diperoleh bahwa terdapat 12 peternak mencapai nilai $\mathrm{R}$ dibawah rata-rata dan hanya 7 peternak yang mencapai nilai $\mathrm{R}$ di atas rata-rata.

Hasil analisis rentabilitas yang diperoleh dari usaha ternak itik petelur di desa Wolaang Kecamatan langowan Timur dapat dilihat bahwa usaha tersebut layak untuk dipertahankan dan dikembangkan karena nilai rentabilitas yang diperoleh sebesar 69\% yang artinya dengan penggunaan modal investasi sebesar Rp.100.000,- mampu menghasilkan laba sebesar Rp.69.000,-Nilai rentabilitas tersebut melebihi kriteria pembanding dalam hal ini suku bunga deposito bank BRI yang berlaku untuk < Rp. 100.000.000 untuk jangka waktu 12 bulan yaitu $6,50 \%$.

\section{KESIMPULAN}

Berdasarkan hasil penelitian menunjukan bahwa :

Nilai Rentabilitas usaha ternak itik petelur di Desa Wolaang Kecamatan Lan gowan Timur sebesar $\mathrm{R}=69 \%$.

Rentabilitas usaha ternak itik petelur lebih besar dari tingkat suku bunga deposito bank BRI.

\section{DAFTAR PUSTAKA}

Budiharjo, K., D. Sumarjono., M. Handayani dan G. Siwi. 2009. Studi Potensi ekonomi Usaha Ternak Itik di Kabupaten Tegal. Prosiding Seminar Kabangkitan Nasional, 20 Mei 2009. p:572-580. 
Kateran, P.P. 2002. Kebutuhan Gizi Itik Petelur dan Itik Pedaging. Wartazoa Vol 12 No 2 Tahun 2002. p:37-46.

Lembong, J. E., 2015. Analisis Break Even Point Usaha Ternak Itik Pedaging (Studi Kasus Pada Usaha Itik Milik Kelompok Masawang di Desa Talikuran Kecamatan Remboken). Jurnal Zootek. Vol. 35 No. 1 : 39-45.

Prayitno, H.,1987. Petani, Desa dan Kemiskinan. BPFE. Yogyakarta.

Riadi. 2006. Analisis Pengaruh Rasio Aktivitas Terhadap Rentabilitas Ekonomi Pada Perusahaan Plastics and Glass Products yang Go Publik di Bursa Efek Jakarta selama tahun 2002-2006. Jurnal Ekonomi dan Bisnis Indonesia, Vol. 15, No. 3: pp. 294-312. Pramesti, Getut,2006

Riyanto, Bambang, 1999. Dasar-dasar pembelanjaan Perusahaan. Edisi 4. Yogyakarta

Simanjuntak, P.J. 1998. Jurnal Analisis Penyerapan Dan Curahan Tenaga Kerja Keluarga Pada Usaha Peternakan.

Supriadi, Yoyon dan Fasriani. 2011. Pengaruh Modal Kerja terhadap Tingkat Likuiditas dan Profitabilitas. Jurnal Ilmiah Ranggading volume 11 No. 1, April 2011:1-11.

Taufik, D.K., Isbandi dan Dyah M. 2013 Analisis Pengaruh Sikap Peternak Terhadap pendapatan Pada Usaha Peternakan Itik Di Kelurahan Pesurungan Lor Kota Tegal. Fakultas
Peternakan. Universitas Dipenegoro. Semarang. JITP Vol. 2 No. 3.

Weston, J. Fred. Dan T. E. Copeland. (1995). Manajemen Keuangan. Edisi Kesembilan. Jilid 1. Terjemahan. Jakarta : Binarupa Aksara.

Yuwono, Dian Maharso. 2012. Budidaya Ternak Itik Petelur. Badan Penelitian dan Pengembangan Pertanian. Balai Besar Pengkajian dan Pengembangan Teknologi Pertanian. Balai Pengkajian Teknologi Pertanian. Jawa Tengah. 